\title{
HUBUNGAN ANTARA RESPON POSITIF SISWA DENGAN HASIL BELAJAR MELALUI METODE OBSERVASI LAPANGAN PADA METERI EKOSISTEM KELAS VII SMP NEGERI 38 BATAM
}

\section{THE RELATIONSHIP BETWEEN THE STUDENTS POSITIVE RESPONSE AND LEARNING OUTCOMES USING FIELD OBSERVATION METHOD ON ECOSYSTEM MATERIAL AT CLASS VII SMPN 38 BATAM}

\author{
Christina Situmorang ${ }^{1}$, Dahrul Aman Harahap ${ }^{2 *}$, Rahmi $^{3}$ \\ ${ }^{123}$ Program Studi Pendidikan Biologi, FKIP, Universitas Riau Kepulauan, Batam \\ *Korespondensi : darul_harahap@yahoo.com
}

\begin{abstract}
Abstrak
Penelitian ini bertujuan mengetahui hubungan antara respon positif siswa dengan hasil belajar melalui metode observasi lapangan pada materi ekosistem kelas VII SMP Negeri 38 Batam. Data penelitian untuk variabel X1 dikumpul dari lembar observasi siswa dan penilaian respon positip, sedangkan untuk hasil belajar atau sebagai variabel X2 dikumpulkan dari tes pilihan ganda yang dilakukan diakhir pembelajaran. Populasi pada penelitian adalah seluruh siswa kelas VII terdiri dari 4 kelas dan populasi sampel diambil dengan menggunakan teknik claster random sampling dan terpilih kelas VII.A dan kelas VII.B sebagai sampel. Hasil uji hipotesis menggunakan pendekatan Uji-t menunjukkan terdapat hubungan antara respon positif siswa dengan hasil belajar, yakni $t_{\text {hitung }}(0,346)>t_{\text {tabel }}(0,235)$.
\end{abstract}

Kata Kunci: Observasi lapangan, Respon positif siswa, Hasil belajar siswa

\begin{abstract}
This research aims to determine the relationship between student positive responses and students learning outcomes using field observation method on ecosystems material at class VII SMP Negeri 38 Batam. The research data for variables XI collected from student observation sheet and positive response ratings, while for learning outcome or as X2 collected from multiple-choice test which done at the end of learning. The population in the study were all students of class VII consisting 4 classes and sample populations was taken by using random sampling cluster and class VII.A was elected and VII.B class as a sample. The results of hypothesis testing using t-test approach demonstrated an association between positive responses of students and learning outcomes, namely $t_{\text {count }}(0.346)>t_{\text {table }}(0.235)$.
\end{abstract}

Keywords: Field observations, student positive response, Student learning outcomes.

\section{PENDAHULUAN}

Kegiatan utama dalam proses pendidikan di sekolah adalah kegiatan belajar mengajar. Proses belajar mengajar yang ada merupakan penentu keberhasilan dalam mencapai tujuan pendidikan. Siswa yang belajar diharapkan mengalami perubahan baik dalam bidang pengetahuan, pemahaman, ketrampilan, nilai dan sikap. Perubahan tersebut dapat tercapai bila ditunjang berbagai macamfaktor, salah satunya adalah mengenai respon 
siswa pada proses pembelajaran.Dalam proses pembelajaran sains, adanya respon positif dari siswa sangat memegang peranan penting untuk meningkatkan rasa ingin tahu siswa terhadappelajaran sains. Siswa yang memiliki respon belajar positif cendrung untuk lebihaktif, kreatif, dan berani mengambil setiap kesempatan, misalnya dalam bertanya,memberikan ide - ide dan menerangkan kepada teman-temannya apabila ada halhalyang kurang dipahami oleh temannya. Hal ini merupakan impilaksi dari caraguru dalam mengelola pembelajaran, artinya dalam melaksanakan proses belajarmengajar sains peranan guru sangat dituntut agar siswa memberikan respon positifdalam belajar kerena dengan adanya repon positif tersebut setidaknya dapatmemahamkan siswa bahwa sains itu merupakan pelajaran yang menyenangkan. Menurut putra (2012) belajar merupakan prosesadaptasi atau penyesuaian tingkah laku yang berlangsung secara progressif.Tingkah laku dikontrol oleh stimulasi dan respon yang diberikan siswa.Adapunpengertian dari respon siswa adalah perilaku yang lahir sebagai hasil masuknya stimulus yang diberikan guru kepadanya.

Respon positif yang diberikan siswa pada saat pembelajaran berlangsung akan dilihat dengan lembar observasi siswa di lapangan, dimana lembar observasi menurut Putra (2012) adalah lembar yang digunakan untuk mengobservasi keberadaan suatu benda atau kemunculan berbagai aspek keterampilan yang diamati, peneliti akan melihat tanggapan siswa yang positif pada saat pembelajaran berlangsung.

Kurangnya respon positif yang diberikan siswa terhadap pembelajaran yang dilakukan di sekolah mengakibatkan kurangnya hasil belajar siswa pada saat tes dilakukan oleh guru bidang studi biologi di SMP Negeri 38 Batam, dan hal tersebut terbukti pula pada saat peneliti melakukan observasi di sekolah tersebut. Banyak siswa yang ditemukan yang belum memahami materi yang diajarkan, karena siswa tidak memberikan respon positif pada saat pembelajaran dilakukan. Menurut Siskandar (2012) dalam Putra (2012) menjelaskan bahwa penilaian dapat dilakukan dengan tiga tehnik yakni lisan,tertulis dan perbuatan atau melakukan sendiri. Teknik yang dilakukan tergantung berbagai faktor seperti waktu, dana, peralatan yang diperlukan,serta sifat dari materi yang akan dinilai atau diajukan.

Penilaian termasuk salah satu bagian yang penting dalam kegiatan pembelajaran, karena kegiatan ini akan menjadi cermin untuk melihat perkembangan dan kemajuan belajar siswa dari waktu kewaktu. Selaian itu penilaian memberikan gambaran kepada 
guru tentang tingkat pencapaian prestasi belajar antara seorang siswa yang satu dengan siswa yang lain. Suatu proses penilaian juga berguna untuk melihat keberhasilan suatu proses pembelajaran yang telah dilakukan oleh seorang guru, seperti strategi dan metode yang dipilih sudah tepat atau belum.

Dimana peneliti menggunakan suatu metode yang mungkin dapat mendorong siswa untuk memberikan respon yang positif pada saat proses pembelajaran berlangsung, metode yang diangkat oleh peneliti untuk memecahkan masalah tersebut adalah dengan metode observasi lapangan. Dimana dengan menggunakan metode observasi lapangan ini siswa akan diajak belajar diluar kelas dan melihat langsung bagaimana lingkungan hidup mereka, siswa akan dituntut untuk lebih aktif dan kreatif dalam melakukan pembelajaran diluar kelas. Menurut Stamboel (1986) dalam Rahardjo (2013) menyatakan bahwa yang dimaksudkan dengan metode observasi ialah suatu pengamatan dalam jangka waktu tertentu dan dalam suatu situasi sosial yang bersifat "bebas"ataupun bermaksud dimana sisabjek tidak merasa diamati.

\section{METODOLOGI}

Jenis penelitian ini adalah korelasional dimana akan dilihat hubungan antara variabel $\mathrm{X}$ (respon positif) dengan variabel $\mathrm{Y}$ (hasil belajar). Penelitian ini direncanakandimulai dari bulan April sampai dengan bulan Juni 2014 yang bertempat di SMP Negeri 38 Batam. Populasi yang digunakan dalam penelitian tersebut adalah seluruh siswa kelas VII SMP Negeri 38 Batam, dimana jumlah kelas di sekolah tersebut terdapat 4 kelas dengan \pm 38 orang/kelas.

Dalam penelitian ini sampel penelitian diperoleh dengan menggunakan teknik claster random (claster random sampling). Dimana sample batas minimal 25\% dari populasi, jumlah populasi 155 x 25\% = 38.75, diketahui jumlah siswa per kelas \pm 36 siswa, maka sample menjadi 2 kelas agar data yang dihasilkan lebih banyak, maka kelas yang di dapat adalah kelas VIIa dan kelas VIIc dan cara pengambilan sample dua kelas tersebut digunakan tehnik cluster random sederhana dengan sistem undian agar anggota populasi dianggap homogen. Katagori respon positip masuk kedalam variabel $\mathrm{X}$ atau variabel bebas yakni merupakan karakteristik yang dimiliki siswa dalam pelajaran biologi yang dapat diperoleh dengan menggunakan lembar observasi siswa yang disusun untuk tujuan penelitian ini, sedangkan variabel $\mathrm{Y}$ atau variabel terikat yang menjadi fokus penelitian 
yang merupakan pencapaian hasil belajar siswa setelah mengikuti pembelajaran terhadap suatu kompetensi dasar yang telah ditetapkan dan dijabarkan dalam berbagai indikator penilaian yakni nilai tes yang diperoleh siswa dari keseluruhan jawaban yang benar dibagi dengan keseluruhan jumlah soal yang dikalikan seratus dan dirumuskan sebagai berikut :

$$
\text { Nilai hasil belajar }=\frac{\text { jawaban yang benar }}{\text { keseluruhan jumlah soal }} \times 100
$$

Uji instrumen meliputi; uji Validitas Instrumen untuk menunjukan tingkat kesahihan suatu instrument, (Misbahuddin 2004) menggunakan koefisien korelasi biserial $\left(\mathrm{r}_{\text {bis }}\right)$; uji Realibilitas adalah tingkat ketetapan, ketelitian atau keakuratan sebuah instrument menggunakan ; kemudian dilanjutkan dengan Uji Data penelitian yaitu; Uji normalitas adalah uji prasayarat tentang kelayakan data untuk dianalisis dengan menggunakan statistik, digunakan adalah uji Kolmogrov-smirnov dan uji Homogenitas dengan $F_{\text {nol }}$ nilai varian terbesar dibagi varian terkecil). Selanjutnya adalah pengujian hipotesis menggunakan koefisien korelasi pendekatan uji t (t-test) serta mencari nilai Koefisien Penentu/ Kontribusi yang dirumuskan sebagai berikut : KP $=(r)^{2}$ x $100 \%(r=$ koefisien determinasi)

\section{PEMBAHASAN}

Data yang diperoleh dari lembar observasi siswa yang akan dideskripsikan dengan sebarannya. Data yang dimaksud yaitu respon positif siswa yang dapat dilihat dari lembar observasi siswa menjadi variabel bebas (X), sedangkan hasil belajar siswa yang dapat dilihat dari tes akhir menjadi variabel terikat (Y). Dimana penilaian dari respon positif siswa didapat dari dua penilaian yang pertama dari hasil lembar observasi siswa dan lembar penilaian guru yang dilakukan pada saat peserta didik melakukan observasi dilapangan. Pada saat peserta didik melakukan observasi di lapangan sekolah peneliti akan memberikan nilai atau skor kepada peserta didik dengan menggunakan nomor punggung siswa yang telah diberikan sebelumnya, peserta didik akan melakukan observasi dengan menggunakan lembar observasi yang telah disediakan oleh peneliti. Didalam lembar observasi siswa di lapangan terdapat beberapa pertanyaan yang harus dijawab oleh setiap peserta didik. 
Maka dari hasil lembar observasi yang didapat akan digabungkan dengan hasil nilai yang diberikan oleh guru saat peserta didik melakukan observasi di lapangan, dan akan dilanjutkan dengan uji persyaratan analisis yang menggunakan uji normalitas dan uji linieritas serta melakukan pengujian homogenitas. Setelah uji persyaratan analisis dihasilkan akan dilanjutkan dengan uji hipotesis dan uji signifikansi. Maka dengan mengikuti tahap yang telah ditentukan tersebut akan terlihat adakah hubungan antara respon positif siswa dengan hasil belajar.

Nilai maximum yang dihasilkan peserta didik untuk respon positif 90 sedangkan untuk hasil belajar nilai yang dihasilkan sekitar 91, sedangkan untuk nilai minimum respon positif siswa nilai yang dihasilkan peserta didik 70 dan untuk hasil belajar mendapat nilai 70. Pada Tabel 1 dihasilkan juga median dari data respon positif dan hasil belajar serta standart devision dan nilai range dari kedua variabel yaitu variabel terikat dan variabel bebasatau variabel $\mathrm{X}$ dan variabel $\mathrm{Y}$, hasil data yang ditampilkan pada tabel frekuensi statistik tersebut didapat berdasarkan dari data-data peserta didik ketika melakukan kegiatan pembelajaran dan untuk lebih memperjelas nilai yang dihasilkan peserta didik dapat dilihat pada tabel dibawah ini.

Tabel 1. Respon positif dan hasil belajar

\begin{tabular}{lcc}
\hline \multicolumn{1}{c}{ PARAMETER } & OBSERVASI & HASIL BELAJAR \\
\hline $\mathrm{N}$ & 73 & 73 \\
Mean & 80.55 & 79.89 \\
Std. Error of Mean & .635 & .630 \\
Median & 81.00 & 81.00 \\
Std. Deviation & 5.426 & 5.387 \\
Variance & 29.446 & 29.016 \\
Range & 20 & 21 \\
Minimum & 70 & 70 \\
Maximum & 90 & 91 \\
Sum & 5880 & 5832 \\
\hline
\end{tabular}

Distribusi frekuensi skor variabel Respon Positif Siswa, hasil data yang telah diperoleh lebih banyak peserta didik yang mendapatkan nilai antara 81 sampai 85 yang menghasilkan frekuensi relatif 38\% dan nilai tertinggi kedua, banyak peserta didik yang mendapatkan nilai antara 70 sampai 75 yang menghasilkan frekuensi relatif $26 \%$, serta nilai tertinggi yang ketiga adalah peserta didik yang mendapatkan nilai antara 76 sampai 80 yang menghasilkan frekuensi relatif hanya $16 \%$. 
Tabel 2. Interval Kelas Observasi

\begin{tabular}{cccc}
\hline No & Kelas Interval & Frekuensi Absolut & Frekuensi Relatif \\
\hline 1 & $70-75$ & 19 & $26 \%$ \\
2 & $76-80$ & 14 & $19 \%$ \\
3 & $81-85$ & 28 & $38 \%$ \\
4 & $86-90$ & 12 & $16 \%$ \\
\hline & TOTAL & $\mathbf{7 3}$ & $\mathbf{1 0 0 \%}$ \\
\hline
\end{tabular}

Interval kelas dari hasil belajar yang dihasilkan berdasarkan nilai yang didapat peserta didik saat dilakukan test akhir belajar seperti tabel dibawah ini menampilkan frekuensi absolut dan frekuensi relatif.

Tabel 3. Interval Kelas Hasil Belajar

\begin{tabular}{cccc}
\hline No & Kelas Interval & Frekuensi Absolut & Frekuensi Relatif \\
\hline 1 & $70-75$ & 18 & $24,7 \%$ \\
2 & $76-80$ & 18 & $24,7 \%$ \\
3 & $81-85$ & 30 & $41,0 \%$ \\
4 & $86-90$ & 6 & $8,20)$ \\
4 & $91-95$ & 1 & $1,30 \%$ \\
\hline & TOTAL & $\mathbf{7 3}$ & $\mathbf{1 0 0 \%}$ \\
\hline
\end{tabular}

Tabel 4. Hasil Uji Normalitas Kolmogorov-Smirnov

\begin{tabular}{llcc}
\hline & & Observasi & Hasil Belajar \\
\hline $\mathrm{N}$ & & 73 & 73 \\
Normal Parameters & Mean & 80.55 & 79.89 \\
& Std. Deviation & 5.426 & 5.387 \\
Most Extreme & Absolute & 0.128 & 0.152 \\
Differences & Positive & 0.128 & 0.121 \\
& Negative & -0.104 & -0.152 \\
Kolmogorov-Smirnov Z & 1.092 & 1.298 \\
Asymp. Sig. (2-tailed) & 0.184 & 0.069 \\
\hline
\end{tabular}

Tabel 5. Hasil Uji Persyaratan Linieritas (di Uji Persamaan Regresi)

\begin{tabular}{|c|c|c|c|c|c|c|c|}
\hline \multicolumn{3}{|c|}{ Parameter } & $\begin{array}{l}\text { Sum of } \\
\text { Square }\end{array}$ & Df & $\begin{array}{c}\text { Mean } \\
\text { Square }\end{array}$ & $\mathbf{F}_{\text {Count }}$ & Sig. \\
\hline \multirow{6}{*}{$\begin{array}{c}\text { Hasil } \\
\text { Belajar } \\
\text { VS } \\
\text { Observasi }\end{array}$} & \multirow{4}{*}{$\begin{array}{c}\text { Between } \\
\text { Groups }\end{array}$} & Combine & 366.349 & 15 & 24.423 & .808 & .664 \\
\hline & & Linierity & 26.134 & 1 & 26.134 & .865 & .356 \\
\hline & & $\begin{array}{c}\text { Deviation } \\
\text { of }\end{array}$ & 340.216 & 14 & 24.301 & .804 & .661 \\
\hline & & Linierity & & & & & \\
\hline & \multicolumn{2}{|c|}{ Within Group } & 1722.774 & 57 & 30.224 & & \\
\hline & \multicolumn{2}{|c|}{ TOTAL } & 2089.123 & 72 & & & \\
\hline
\end{tabular}


Pengujian homogenitas adalah pengujian mengenai sama tidaknya variansi-variansi dua buah distribusi atau lebih. Uji homogenitas yang akan dibahas dalam tulisan ini adalah Uji Homogenitas Variansi. Uji homogenitas dilakukan untuk mengetahui apakah data dalam variabel $\mathrm{X}$ dan $\mathrm{Y}$ bersifat homogen atau tidak.Hasil yang dapat ditemukan pada pengujian homogenitas tersebut normal dimana data variabel X dan Y bersifat homogen, dapat dilihat di dalam tabel dibawah ini, dimana 0,639>0,05

Tabel 6. Hasil Uji Homogenitas

\begin{tabular}{cccc}
\hline Levene Statistik & Df $_{\mathbf{1}}$ & Df $_{\mathbf{2}}$ & Significance \\
\hline 0.789 & 10 & 61 & 0.639 \\
\hline
\end{tabular}

Uji hipotesis adalah metode pengambilan keputusan yang didasarkan dari analisis data, baik dari percobaan yang terkontrol, maupun dari observasi (tidak terkontrol). Dalam statistik sebuah hasil bisa dikatakan signifikan secara statistik jika kejadian tersebut hampir tidak mungkin disebabkan oleh faktor yang kebetulan, sesuai dengan batas probabilitas yang sudah ditentukan sebelumnya. Uji hipotesis tersebut sangat penting dilakukan karena hasil yang ditemukan akan menjadi penentu dalam penelitian ini, terdapat atau tidak hubungan antara respon positif siswa dan hasil belajar. Pada tabel dibawah ini dapat terlihat bahwa ada hubungan yang positif dan signifikan dari respon positif siswa dengan hasil belajar siswa karena hasil yang di dapat yaitu 0,346>0,235.

Tabel 7. Rekapitulasi Korelasi Hasil Belajar dengan Iklim Belajar

\begin{tabular}{clcc}
\hline PARAMETER & \multicolumn{1}{c}{ KORELASI } & OBSERVASI & $\begin{array}{c}\text { HASIL } \\
\text { BELAJAR }\end{array}$ \\
\hline \multirow{3}{*}{ Observasi } & Pearson Correlation & 1 & 0.112 \\
& Significan (2-tailed) & - & 0.346 \\
& $\mathrm{~N}$ & 73 & 73 \\
\cline { 2 - 4 } & Pearson Correlation & 0.112 & 1 \\
Hasil Belajar & Significan (2-tailed) & 0.346 & - \\
& $\mathrm{N}$ & 73 & 73 \\
\hline
\end{tabular}

Nilai Koefisien Determinasi $\left(\mathrm{R}^{2}\right)=0.013(1.3 \%)$ artinya ada faktor lain mempengaruhi hasil belajar yakni sebesar $98,7 \%$, hal ini menunjukkan bahwa faktor lain yang sangat berpengaruh untuk menurunkan nilai hasil belajar. 


\section{KESIMPULAN}

Berdasarkan hasil penelitian dan pembahasan yang sudah dipaparkan, maka dapat ditarik beberapa kesimpulan sehubungan dengan tujuan penelitian ini yaitu : Tidak terdapat hubungan antara respon positif siswa dalam proses pembelajaran dengan hasil belajar melalui metode observasi lapangan, dimana nilai nyata yang membuktikannya yaitu rendahnya nilai korelasial (r) yakni sebesar 0,346 atau 34,6\% dan sebesar 0,235 atau 23,5\%. Maka dari hasil yang ditemukan tersebut dapat diketahui bahwa tidak terdapat hubungan yang singnifikan antara kedua variabel dengan menggunakan metode observasi lapangan.

\section{REFERENSI}

Novianti, 2013. IPA TERPADU untuk SMP-MTS kelas VII, Penerbit Yarama Widya. Bandung.

Putra, 2012. Desain Evaluasi Belajar Berbasis Kinerja, Penerbit Diva Press. Jember.

Sugiyono, 2013. Metode Penelitian Kuantitatif dan $R \& D$. Bandung. Penerbit Alafabeta

Sutikno, 2009. Belajar dan Pembelajaran, Penerbit Holistika. Lombok.

Sutikno,2013. Belajar dan pembelajaran "Upaya Kreatif dalam Mewujudkan Pembelajaran yang Berhasil. Holistika. Lombok.

Vera, 2012. Metode Mengajar Anak di Luar Kelas, Penerbit Diva Press. Yogyakarta.

Efendi, Y., Ramses, R., \& Styvany, S. (2014). Pengaruh Pembelajaran Kooperatif Student Facilitator And Explaining Terhadap Hasil Belajar Siswa Pada Pembelajaran Biologi Kelas Viii Smp Negeri 10 Batam Tahun Pelajaran 2013/2014. SIMBIOSA, 3(2). 